\title{
REVISÃO BIBLIOGRÁFICA ACADÊMICA SISTEMÁTICA SOBRE DUBLAGEM BRASILEIRA EM UMA PESQUISA DE DOUTORADO
}

\begin{abstract}
Nívea Guimarães Doria
Doutoranda em Letras - Linguística - pela Universidade do Estado do Rio de Janeiro (UERJ)

niveadoria@uol.com.br.
\end{abstract}

\section{RESUMO}

Todas as atividades acadêmicas prescindem de uma fundamentação teórica e saber quais os caminhos seguidos por demais pesquisadores que abordaram anteriormente nossa temática de interesse nos ajuda a decidir a forma pela qual empreenderemos nossa própria pesquisa. A dublagem é uma modalidade de tradução audiovisual que, na última década, vem se consolidando como a principal no mercado brasileiro. Contudo, ainda é exígua a produção acadêmica sobre o tema. Este trabalho, à luz do proposto por Vergnano-Junger (2015), objetiva refletir sobre isso e ser uma referência a quem se interessa a pesquisar academicamente sobre a dublagem brasileira. Concluímos que, apesar de ainda escassa, vem aumentando o número de trabalhos sobre o tema nos últimos dez anos no Brasil, embora careça de trabalhos que retratem a realidade desse mercado no país.

Palavras-chave: dublagem brasileira, compreensão leitora, revisão bibliográfica, tradução audiovisual.

\section{RESÚMEN}

Todas las actividades académicas necesitan una fundamentación teórica. Además, saber quales son los caminos seguidos por los demás investigadores que abordaron ya la misma temática nos ayuda a elegir la manera por la cual haremos nuestra investigación. El doblaje es una modalidad de traducción audiovisual que, en la última década, viene consolidándose como la principal en el mercado brasileño. Sin embargo, todavía es exigua la producción académica acerca del tema. Este artículo sigue lo propuesto por Vergnano-Junger (2015), con objectivos de reflexionar sobre eso y ser uma referencia a quienes se interessan a investigar academicamente el doblaje brasileño. Concluimos que, aunque haya escasez, se viene aumentando el número de investigaciones sobre el tema en la última década entre los científicos brasileños.

Palabras clave: doblaje brasileño, compreensión lectora, revisión bibliográfica, traducción audiovisual. 


\section{Introdução}

A dublagem possui um papel social importante dentro da sociedade brasileira: possibilitar o acesso a produtos culturais audiovisuais provenientes de países falantes de outras línguas para o máximo de pessoas. Analfabetos, deficientes visuais, crianças ainda não alfabetizadas, idosos e pessoas com demais dificuldades de leitura não têm condições de acessarem tais produtos por meio da legenda. Tampouco é a maior parte da população que possui níveis avançados de proficiência em línguas estrangeiras diversas para assistirem a filmes, séries, animações, etc. com o áudio em suas línguas originais. Então, pesquisar cientificamente a dublagem mostra-se relevante dentro de nosso contexto sociocultural.

Ao elaborarmos nosso projeto de pesquisa para o ingresso no programa de pósgraduação ao qual nos filiamos, deparamo-nos com poucas produções acerca da dublagem que o fundamentassem ainda que filtrando as áreas em que a dublagem está mais diretamente inserida: Artes Cênicas (a única exigência para exercer a profissão de dublador é o registro profissional de ator na DRT), Comunicação (tanto na área específica de cinema quanto em relação ao audiovisual) e Estudos da Tradução (por tratar-se de uma das modalidades de tradução audiovisual).

Devido a esse cenário acadêmico escasso, a importância social e o aumento da demanda de dublagem no mercado nos últimos anos (por parte dos canais de TV por assinatura, serviços de streaming e cinema), decidimos sistematizar nossas buscas bibliográficas e trabalhar criticamente os resultados. Procuramos pelo termo "dublagem" no Scholar Google, Portal de Periódicos da Capes e Banco de Teses \& Dissertações - 
CAPES, restringindo aos últimos 10 anosi. Objetivando, assim, que este artigo sirva de referência para quem se interessar academicamente sobre a área futuramente.

Seguimos neste artigo o postulado por Cristina Vergnano-Junger (2015) em relação à importância da revisão bibliográfica no contexto acadêmico e como empreendê-la em fontes on-line. Recorremos à dissertação de Bruna Leite (2017) no que tange aos gêneros acadêmicos pesquisados na internet e os buscadores utilizados para essa atividade.

\section{A revisão bibliográfica inserida na pesquisa acadêmica}

A revisão bibliográfica é uma etapa importante em atividades acadêmicas, tanto na graduação quanto na pós-graduação. Vergnano-Junger (2015) diz que a revisão bibliográfica é uma atividade eminentemente leitora, "requerendo método, cuidado, utilização de estratégias cognitivas de ingerência, monitoramento, seleção, comparação e estabelecimento de conexões com outros autores, textos e, por vezes, áreas de conhecimento" (VERGNANO-JUNGER, 2015, p. 67). A autora também destaca as razões pelas quais essa etapa é tão importante dentro de atividades acadêmicas:

(a) fundamenta o problema e a pesquisa que se quer desenvolver, contribuindo para sua solidez e cientificidade; (b) ajuda a delimitar caminhos, eliminando aqueles já exauridos e ajudando a aprofundar os menos explorados; (c) demonstra a erudição, capacidade de investigação e seriedade do pesquisador e (d) valoriza e reconhece que a ciência é construída por meio de trajetórias que incluem diversos pesquisadores e trabalhos. [...] Está, também, relacionada com a produção de novos textos acadêmicos, com os quais vai dialogar e, por meio dos quais, poderá deixar manifesto o próprio processo leitor prévio do sujeito (VERGNANO-JUNGER, 2015, p. 67). 
A autora situa a pesquisa bibliográfica empreendida em contexto acadêmico como uma das práticas de letramento". Este "ocorre num processo social, cultural, linguístico e cognitivo que se modifica e enriquece ao longo da vida dos indivíduos, membros de sociedades letradas" (VERGNANO-JUNGER, 2015, p. 58). Embora a questão seja abordada pela autora do ponto de vista do ensino-aprendizagem universitário, trata-se de um ponto central para toda pesquisa acadêmica e, por isso, vale ressaltá-la neste artigo.

Escolhemos empreender nossa revisão bibliográfica através do meio digital, pois as fontes de divulgação e pesquisa foram-se ampliando com o advento e popularização da Internet. Abrindo, assim, "um novo espaço [...] [de] armazenamento, apresentação e distribuição de textos: o virtual" (VERGNANO-JUNGER, 2015). Atualmente, não precisamos mais ir a uma biblioteca para termos acesso a revistas e periódicos acadêmicos, tampouco para consultarmos teses e dissertações. Através da Web-e certas publicações são exclusivas desse meio - temos acesso a produções científicas das mais diversas áreas, não apenas de todos os estados brasileiros, como também de vários outros países.

Leite (2017) discute sobre gêneros digitais mais lidos por pessoas inseridas no meio acadêmico. Em uma enquete realizada via rede social Facebook, tendo este tipo de perfil como público respondente maioritário, a autora traçou que grande parte de seus sujeitos se utilizavam de buscadores on-line em sua navegação. Devido a esses resultados, Leite (2017) introduz o que chama de gênero resultado de busca. Outro gênero muito citado por esses sujeitos é o de artigos acadêmicos, que, também, são mais facilmente encontrados em buscadores especializados. 


\section{Sistematizando nossa revisão bibliográfica}

Quando iniciamos nossas buscas por textos acadêmicos a respeito da dublagem tanto em livrarias quanto em buscadores on-line, de maneira assistemática -, encontramos um cenário muito diferente do achado, por exemplo, sobre compreensão leitora. Embora ambas as temáticas sejam passíveis de estudos em diversas áreas do conhecimento, encontramos discrepância na quantidade de textos sobre elas.

Devido a essa percepção, decidimos sistematizar nossa etapa de revisão de bibliografia acadêmico-científica, feita via Internet. Como esses materiais podem trazer informações destoantes que precisam ser verificadas e devido à efemeridade do meio virtual e integração de conteúdos, baseamos nossa metodologia nas seguintes pautas práticas levantadas por Vergnano-Junger (2015):

a) Preferir buscadores especializados, voltados para materiais acadêmicos, ou portais de publicações acadêmico-científicas.

b) Realizar buscas utilizando parâmetros que refinem os resultados: intervalos de datas de publicação (com ênfase às mais recentes); tipo de documentos (.pdf, ou .html, por exemplo); tipo de escrito (resumos, artigos completos).

c) [...] fazer uma seleção inicial, pensando sempre no tema e problema em foco, utilizando títulos como primeiro apoio, passando, depois, para os resumos.

d) [...] reconhecer e avaliar: autores, fonte da publicação (inclusive sua classificação), confirmação da data de publicação. Caso algum desses itens esteja ausente, pouco claro ou conflitante, há recursos que a própria internet nos fornece para esclarecimentos. [...]

e) Uma última prática pode ser a ampliação da pesquisa, com base nas referências e bibliografias constantes nos textos selecionados [...] (VERGNANO-JUNGER, 2015, p. 70). 
A dublagem é um termo polissêmico. Tanto pode significar uma modalidade da tradução audiovisual, que se caracteriza pela substituição do conteúdo verbal oral na língua original por sua versão na língua alvo (FRANCO; ARAÚJO, 2011), como pode ser o lip sinc ou mesmo, segundo Nascimento (2014), uma ressonorização na etapa de pósprodução na mesma língua. No nosso caso, pesquisamos a modalidade de tradução audiovisual.

Evidencia-se, portanto, a pertinência de tê-la como objeto de pesquisa dentro da área de Estudos da Tradução e em Comunicação ou Cinema. Outra área na qual se enquadra é nas Artes Cênicasiii. Já na área de Letras e Linguística, justifica-se por trabalhar diretamente com o uso da língua. Delimitamos, assim, as quatro áreas do conhecimento nas quais realizamos nossas buscas.

Cada país tem suas próprias especificidades dentro do mercado da dublagem como TAV. Podemos destacar, no Brasil, a obrigatoriedade do registro profissional de artista/ator para poder exercer profissionalmente esse trabalho. Outro exemplo que podemos apontar de especificidade é sua consolidação como modalidade de tradução audiovisual. Freire (2011) aponta que a precariedade nos equipamentos das salas de projeção foi fundamental para que a dublagem não se consolidasse nos cinemas brasileiros por décadas. Já na Espanha, a ditadura franquista determinou que todo filme estrangeiro fosse exibido com dublagem, que até hoje é a principal modalidade de TAV naquele país. Portanto, optamos por delimitar nossa pesquisa ao mercado brasileiro de dublagem.

Para a checagem das fontes, utilizamos a avaliação do Qualis Capes mais recente, que pode ser consultada na Plataforma Sucupira. Selecionamos os artigos publicados em revistas e periódicos com avaliação entre $\mathrm{A} 2$ e $\mathrm{B} 2$, por serem as notas mais elevadas. 
Nessa mesma plataforma, temos também acesso às avaliações da Capes dos cursos de Pós-Graduação credenciados no MEC. No Banco de Teses \& Dissertações - CAPES, selecionamos trabalhos defendidos em programas avaliados com notas acima de 4, considerados de bons a excelentes. Por nossa pesquisa ser em nível de Doutorado, optamos por não selecionar monografias e trabalhos de conclusão de curso (TCC) de graduação e pós-graduação lato sensu.

Estabelecemos, então, os seguintes critérios para a seleção dos textos encontrados:

1) Gêneros textuais: artigos acadêmicos, dissertações de mestrado e teses de doutorado;

2) Temática: dublagem como modalidade de TAV, feita de modo profissional no Brasil para o mercado brasileiro;

3) Período: 2007-2017;

4) Áreas de conhecimento: Letras/Linguística, Estudos da Tradução, Comunicação/Cinema, Artes;

5) Em relação à checagem das fontes:

a) Artigos - revistas e periódicos classificados como B1, B2, A1 e A2 no Qualis Capes mais recente, consultado através da Plataforma Sucupira;

b) Teses e dissertações - defendidas em Programas de Pós-Graduação stricto sensu com notas acima de 4, segundo avaliação mais recente da Capes. Consulta, através da Plataforma LATTES do CNPq, dos currículos acadêmicos desses autores em busca de outras publicações e apresentações de trabalho sobre o tema.

\section{Os resultados encontrados nos buscadores pesquisados}


A seguir, apresentamos os resultados de nossa revisão bibliográfica. Em seções correspondentes, justificamos as fontes utilizadas para as buscas on-line: Catálogo de Teses \& Dissertações - CAPES, Portal .periódicos. CAPES e Scholar Google. Buscamos, também, no portal Scielo, reconhecida fonte de consulta de textos acadêmicos utilizada por pesquisadores, porém não encontramos nenhum resultado ao consultar o termo "dublagem".

\subsection{O Catálogo de Teses \& Dissertações - CAPES}

A escolha por esse site justifica-se por ser um serviço da Coordenação de Aperfeiçoamento de Pessoal de Nível Superior (CAPES). Essa coordenação trata-se de uma fundação do Ministério da Educação para expansão e consolidação da pósgraduação stricto sensu em território brasileiro (LEITE, 2017). Como seu próprio nome sugere, o site permite a busca de trabalhos de conclusão de cursos de pós-graduação em nível de Mestrado e Doutorado que se encontram hospedados na Plataforma Sucupira, que podem ser baixados para os dispositivos dos pesquisadores.

Em julho de 2017, pesquisamos o termo "dublagem" nesse buscador, resultando em 16 ocorrências. Procedendo à leitura de títulos, resumos e palavras-chave, descartamos 7 por pertencerem a outras áreas de conhecimento: 3 eram sobre música e/ou aspectos culturais e sociológicos; 1 de fonoaudiologia; 1 na área de Direito e 1 na área de Ensino de História/Letramento. Com relação à temática, descartamos 2, pois falam sobre legendagem. Dentre os outros 9 resultados, encontramos 2 teses e 7 
dissertações. 1 dissertação, apesar de ser sobre dublagem como TAV, não se encontra na íntegra e, por isso, foi descartada.

Prosseguindo a leitura das outras seções dos 8 textos encontrados remanescentes (CÓRDULA, 2012; SANTOS, 2013, MENDES, 2007; BARBOSA, 2009; BAHR, 2014; FARIAS, 2014; NASCIMENTO, 2014; SOUZA NETO, 2015), chamou-nos atenção o fato de serem escassas as pesquisas que tenham feito trabalho de campo. Não sendo esta uma temática muito abordada academicamente, a observação do trabalho feito no processo de dublagem brasileira abarcaria as especificações dessa atividade, tornando-se referências para outros pesquisadores. Ademais, por nossa pesquisa seguir essa metodologia, selecionar como fonte bibliográfica outros trabalhos que também o façam permite-nos também filiarmo-nos ao que vem sendo feito nesse sentido. Encontramos com essa característica um trabalho que apresenta apenas entrevistas a profissionais envolvidos nesse processo e outro que traz diferentes metodologias de trabalho de campo.

Nascimento (2014), da área de Comunicação, investiga a dublagem como um processo de gravação de voz em produções audiovisuais, tanto como modalidade de TAV quanto como gravação na etapa de pós-produção de obras audiovisuais. A autora, ainda que não vá a campo, entrevista profissionais da área: dubladores, acadêmicos e técnicos de som. Já a dissertação de Mendes (2007) aborda a dublagem em estúdio, pesquisando o papel tanto do dublador quanto do diretor de dublagem na adaptação final do texto traduzido. Para isso, realiza observações de sessões de gravação, diário da pesquisadora, entrevistas com profissionais da área e um pequeno glossário de jargões da área.

Encontramos, também, dois trabalhos com metodologia experimental, contudo voltados diretamente ao ensino-aprendizagem de espanhol língua estrangeira (ELE): uma dissertação (BARBOSA, 2009) e uma tese (SANTOS, 2013). Ambas usam procedimentos de 
produção de diferentes modalidades de TAV com finalidades pedagógicas com estudantes de graduação. Não há, entretanto, um trabalho de campo do processo de dublagem, ou seja, não trazem um retrato da realidade desse ambiente profissional.

Os demais trabalhos tomam principalmente o produto final e entrevistas de profissionais, tanto de atores originais quanto dos dubladores a outros meios (revistas, sites, vídeos no Youtube, etc.). Ou seja, apresentam metodologias predominantemente documentais, principalmente sobre questões linguísticas: sobre questões fonéticofonológicas, sobre a tradução e adaptação de roteiro de dublagem. Suas fundamentações teóricas baseiam-se majoritariamente em material estrangeiro sobre dublagem. Há, apenas, breves citações a referências brasileiras sobre o tema.

\subsection{O Portal .periódicos. CAPES}

O Portal .periódicos. CAPES também se encontra no site da CAPES e nele se podem encontrar textos acadêmicos de vários gêneros textuais: artigos, dissertações, teses, livros, entrevistas, etc. Como já defendemos no apartado anterior, a CAPES, por ser um órgão governamental que fomenta a pesquisa e a pós-graduação, é uma fonte confiável de consulta (LEITE, 2017). Nesse buscador, há diferenças entre o acesso de uma conexão particular ou de uma feita a partir de dispositivos conectados a redes de IES cadastradas. Efetuamos nossa busca em julho de 2017 a partir de um computador da IES à qual nosso programa de pós-graduação se insere.

No final do mês de junho de 2017, encontramos 18 resultados ao digitarmos o termo "dublagem" no buscador desse portal. Após a leitura de títulos, resumos e palavras-chave, descartamos 16 textos. Seguindo o critério do gênero, eliminamos 6: 4 
inseriam-se em guias de estudante/de profissões, enquanto os outros 2 eram livros. Devido à temática, descartamos 8: 2 sobre dublagem estrangeira; 1 sobre música; 2 sobre formação de ator (dublagem apenas citada); 2 sobre cinema em geral (dublagem apenas citada); 2 sobre legislação de audiovisual (sem questões específicas sobre dublagem).

Selecionamos apenas 2 artigos que atendiam a todos os critérios estabelecidos. Ambos são de mesmo autor (FREIRE, 2011; 2014). São pesquisas documentais na área de Comunicação/Cinema, a respeito do desenvolvimento tecnológico do som, além de aspectos históricos da implementação e consolidação da dublagem como modalidade de TAV no Brasil. O autor consulta e cita artigos e reportagens das épocas abordadas para sustentar suas argumentações. Importante ressaltar que ambos são utilizados nas fundamentações teóricas de outros trabalhos encontrados.

\subsection{O Scholar Google, o Google Acadêmico}

No dia 29 de junho de 2018, realizamos nosso mapeamento no buscador acadêmico do Google. Ao digitarmos "dublagem" no campo de pesquisa e filtrarmos os resultados para o período compreendido entre 2007 e 2017, encontramos uma contagem de 2300 resultados. Ao navegarmos entre páginas com 20 resultados cada, apareceram apenas 48 páginas, sendo a última com apenas 19 resultados. Dessa forma, obtivemos, de fato, um total de 959 resultados. Várias dessas entradas mostraram-se repetidas.

Realizamos, então, uma primeira triagem, lendo os resumos e as palavras-chave de cada uma das entradas, além de utilizarmos a ferramenta de busca do navegador ou do programa leitor de arquivos .pdf para encontrarmos as ocorrências do termo e em que contexto se encontrava. Descartamos 915 resultados com citações muito breves ou com 
dublagem com significados distintos ao de modalidade TAV, além de trabalhos na área de fonoaudiologia, como na pesquisa nos portais da CAPES, por não termos conhecimentos na área. Por fim, identificamos 44 publicações como sendo a respeito ou citando a dublagem como TAV.

Dos resultados pré-selecionados, 12 como já haviam sido encontrados nas pesquisas nos portais da CAPES e examinados de acordo com os critérios supracitados. Restaram, portanto, 32, dentre os quais descartamos: 8 com Qualis abaixo de B2; 1 artigo sem referência bibliográfica e, portanto, sem que pudéssemos aferir seu Qualis; 12 trabalhos de conclusão de graduação e pós-graduação lato sensu; 4 anais de congresso com Qualis abaixo de B2 ou não avaliados. Descartamos, ainda, 1 texto por ser uma resenha e, portanto, fora de nossos critérios.

Dos restantes, todos são artigos acadêmicos em periódicos com classificação acima de B2, sendo que nenhum com trabalho de campo. Pinheiro-Correia (2015) usa o texto dublado para estudo gramatical. Martinez (2011) e Franco e Araújo (2011) falam sobre a tradução audiovisual de forma geral e citam a dublagem. Já Machado (2008) traz uma reflexão sobre dublagem e estrangeirização. 3 deles apresentam metodologia documental -análises partindo de um produto final para falar sobre aspectos da dublagem ou de sua tradução - enquanto os outros dois fazem suas análises a partir de pesquisa bibliográfica acerca do tema. Já o trabalho de Braga (2012) é exclusivamente sobre dublagem. Este apresenta comparações entre as dublagens em diferentes línguas de uma mesma produção cinematográfica. Apresenta, também, uma sugestão de modificação da versão brasileira elaborada pelo próprio autor.

\subsection{Textos selecionados entre os obtidos nos buscadores utilizados}


Apresentamos, abaixo um quadro geral com a síntese dos resultados obtidos em nossa pesquisa, seguindo os critérios apresentados no item 2 deste artigo. Nosso objetivo, com isso, é apresentar uma referência para futuros pesquisadores.

Quadro 1 - Resultados sobre dublagem obtidos em buscadores on-line

\begin{tabular}{|c|c|c|c|c|}
\hline Autor(es)/Data & Gênero & Dublagem (TAV) & Classif. & Área \\
\hline MENDES, 2007 & Dissertação & Sim & 4 & Letras/ Linguística \\
\hline BARBOSA, 2009 & Dissertação & Sim (e outras TAV) & 4 & Letras/ Linguística \\
\hline CORDULA, 2012 & Tese & Sim & 6 & Letras/ Linguística \\
\hline SANTOS, 2013 & Tese & Sim & 5 & Estudos de Tradução \\
\hline BAHR, 2014 & Dissertação & Sim & 4 & $\begin{array}{l}\text { Comunicação; Letras/ } \\
\text { Linguística }\end{array}$ \\
\hline FARIAS, 2014 & Dissertação & Sim & 6 & Letras/ Linguística \\
\hline $\begin{array}{l}\text { NASCIMENTO, } \\
2014\end{array}$ & Dissertação & $\begin{array}{l}\text { Sim (sonorização em } \\
\text { pós-produção) }\end{array}$ & 4 & Comunicação \\
\hline $\begin{array}{l}\text { SOUZA-NETO, } \\
2015\end{array}$ & Dissertação & Sim (e outras TAV) & 4 & Letras/Linguística \\
\hline FREIRE, 2011 & Artigo & Sim & B1 & Comunicação \\
\hline FREIRE, 2014 & Artigo & Sim & $A 2$ & Comunicação \\
\hline $\begin{array}{l}\text { MARTINS; } \\
\text { AMORIM, } 2013\end{array}$ & Artigo & Sim (e outras TAV) & B2 & Tradução \\
\hline MACHADO, 2008 & Artigo & Sim (e outras TAV) & A2 & Tradução \\
\hline $\begin{array}{l}\text { PINHEIRO- } \\
\text { CORREIA, } 2015\end{array}$ & Artigo & Sim (e outras TAV) & B2 & Linguística \\
\hline BRAGA, 2012 & Artigo & Sim & B1 & Tradução \\
\hline MARTINEZ, 2011 & Artigo & Sim (e outras TAV) & B2 & Tradução \\
\hline $\begin{array}{l}\text { FRANCO; } \\
\text { ARAUJO, } 2011\end{array}$ & Artigo & Sim (e outras TAV) & B2 & $\begin{array}{l}\text { Letras/Linguística; } \\
\text { Tradução }\end{array}$ \\
\hline
\end{tabular}

Fonte: A autora, 2018.

\section{Considerações finais}

A busca por bibliografia acadêmica a respeito das temáticas de nossas próprias pesquisas é necessária tanto para compreendermos o estado da arte sobre o assunto, 
como para fundamentá-lo e filiá-lo ao que já vem sendo feito, assim podendo propor novos caminhos a serem seguidos ou aprimorar o que já foi feito. A primeira impressão causada por nossas buscas assistemáticas de textos acadêmicos sobre dublagem, feitas entre 2011 e 2016, de que havia pouco material acadêmico sobre dublagem, levou-nos à presente pesquisa. Esta se propõe a buscar textos acadêmicos que tenham a temática da dublagem, selecionando-os sob critérios estabelecidos de acordo com o proposto por Vergnano-Junger (2015).

Considerando que estabelecemos um período de 10 anos para nossa pesquisa bibliográfica, a contagem de 16 trabalhos a respeito de dublagem mostra-se um tanto escasso. Ao compararmos com os resultados obtidos no Catálogo de Teses e Dissertações CAPES de períodos anteriores a este (4 dissertações e teses entre 1991 e 2006), no entanto, vemos que é um assunto que vem despertando o interesse dos pesquisadores, tanto na área de Estudos de Tradução, quanto na de Letras e Comunicação, principalmente.

É importante, no entanto, atentar que, apesar de esses números estarem aumentando, ainda pouco se pesquisa dentro do estúdio. Há muitos estudos documentais, porém, encontramos apenas o trabalho de Mendes (2007) com metodologia de campo. Esse ponto é importante, pois além das coerções de sincronia entre texto, imagem e som, as adaptações que se houve no texto oral de uma dublagem profissional são responsabilidade tanto do tradutor quanto do trabalho feito em estúdio, de dublador, diretor e técnico de som. Passam, também, por exigências feitas pelo cliente que contrata a empresa de dublagem.

Outro ponto que se destaca nesta pesquisa é que, dentre textos selecionados sob nossos critérios ou não, encontramos apenas 2 autores que defenderam trabalhos para a 
obtenção de títulos de pós-graduação stricto sensu e publicaram artigos. Isso mostra que poucas dessas pesquisas mostram desdobramentos que vão além da obtenção dos títulos. Para corroborar dados, buscamos os currículos LATTES de alguns desses autores e igualmente é pequena a quantidade de mestres cuja pesquisa foi sobre a temática que estão cursando o doutorado, levando sua pesquisa adiante.

Por fim, esperamos que nossa reflexão acerca da escassez de trabalhos acadêmicos sobre dublagem sirva de referência para pesquisadores interessados, porém inseguros de seguir esse caminho. Esperamos, também, ter ajudado a indicar pontos ainda pouco abordados para que a dublagem continue a ser cada vez mais uma temática pesquisada. Seja na área de Letras/Linguística, na de Estudos da Tradução, Comunicação ou mesmo Artes Cênicas.

\section{Referências}

BAHR, Michael P. El Chavo del Ocho/Chaves: Tradução, adaptação, dublagem. 2014. $103 f$. Dissertação (Mestrado em Comunicação e Linguagens, área de concentração: Cinema). Programa de Pós-Graduação Strictu Sensu em Comunicação e Linguagens. Universidade Tuiuti do Paraná. Curitiba, 2014.

BARBOSA, Edilene R. O uso da tradução audiovisual para o desenvolvimento da compreensão oral em língua espanhola. 2009.193 f. Dissertação (Mestrado Acadêmico em Linguística Aplicada). Programa de Pós-Graduação em Linguística Aplicada. Universidade Estadual do Ceará. Fortaleza, 2009.

BRAGA, Guilherme da S. V de Vanilóquio: uma verificação das variações vocabulares nas várias versões em vídeo de $V$ de vingança. In: Conexão Letras: o funcionamento da tradução e os desafios da experiência de traduzir. V. 7 n. 7, 2012. Porto Alegra: Programa de Pós-Graduação em Letras da Universidade Federal do Rio Grande do Sul, 2012.

CORDULA, Maira S. M. Análise fonético-fonológica dos padrões entoacionais do Português brasileiro e do Inglês Norte-Americano no filme Shrek (2001). 2012. 237f. Tese (Doutorado 
em Linguística e Língua Portuguesa). Programa de Pós-Graduação em Linguística e Língua Portuguesa. Universidade Estadual Paulista "Julio Mesquita Filho". Araraquara - SP, 2012.

FARIAS, Raquel R. Tradução para dublagem e variação linguística: um estudo de caso do filme Bastardos inglórios. 2014. 82f. Dissertação (Mestrado em Letras). Programa de PósGraduação em Letras. Universidade Federal do Rio Grande do Sul. Porto Alegre, 2014.

FERNANDES, Lilian. Dublagem na Fox, o desfecho: canal passará a ser totalmente em português. In: $O$ Globo. Rio de Janeiro, 05 jul. 2007. Disponível em: $<$ https://oglobo.globo.com/cultura/dublagem-na-fox-desfecho-canal-passara-sertotalmente-em-portugues-4176867>. Acesso em: 24 ago. 2017.

FRANCO, Eliane P. C; ARAÚJO, Vera S. Questões terminológicas e conceituais no campo da tradução audiovisual (TAV). Tradução em Revista. v. 11. 2011. p. 2. Disponível em: $<$ https://www.maxwell.vrac.pucrio.br/colecao.php?strSecao=resultado\&nrSeq=18884@1\&msg=28\#>. Acesso em 14 ago. 2015.

FREIRE, Rafael. de L. Versão brasileira: contribuições para uma história da dublagem cinematográfica no Brasil nas décadas de 1930 e 1940. Ciberlegenda. n. 24 Sonoridades no Cinema e no Audiovisual. p. 7-18. Rio de Janeiro: UFF, 2011. Disponível em: <http://www.ciberlegenda.uff.br/index.php/revista/article/view/378>. Acesso em: 01 maio 2017.

Dublar ou não dublar: a questão da obrigatoriedade de dublagem de filmes estrangeiros na televisão e no cinema brasileiros. Revista FAMECOS mídia, cultura e tecnologia. v. 21. n. 3. Porto Alegre, 2014. p. 1168-1191. Disponível em: http://revistaseletronicas.pucrs.br/ojs/index.php/revistafamecos/article/view/18347. Acesso em: 10 maio 2017.

GENESTRETI, Guilherme. Pesquisa revela que 6 em 10 brasileiros preferem filmes dublados. IN: Folha de São Paulo. São Paulo, 09 ago. 2015. Disponível em <https://www1.folha.uol.com.br/ilustrada/2015/08/1666126-pequisa-revela-que-6-em10-brasileiros-preferem-filmes-dublados.shtml>. Acesso em: 10 ago. 2015.

LEITE, Bruna R. V. Caracterizando suporte digital e gêneros textuais em dispositivos fixo e móvel. 2017.183 f. Dissertação (Mestrado em Linguística) - Programa de Pós-Graduação em Letras, Universidade do Estado do Rio de Janeiro, Rio de Janeiro, 2017.

MACHADO, Arlindo. Todos os filmes são estrangeiros. Matrizes. v. 2, n. 1. São Paulo, 2008. p. 97-111. Disponível em: <http://producao.usp.br/handle/BDPI/32350>. Acesso em: 10 maio 2017. 
MARTINEZ, Sabrina L. Tecnologia digital, acessibilidade e novos mercados para o tradutor universal. IN: Tradução em revista. v. 11. 2011. Disponível em:

$<$ https://www.maxwell.vrac.puc-

rio.br/colecao.php?strSecao=resultado\&nrSeq=18880@1\&msg=28\#>. Acesso em: 29 jun. 2018.

MARTINS, Raíra V.; AMORIM, Lauro M. Legendagem e dublagem: diferenças na tradução do humor. Traduzires 4. Rio de Janeiro, 2013.

MENDES, Renata H. R. Diretor de dublagem e dublador: os co-autores da tradução para dublagem. 2007. 223f. Dissertação (Mestrado em Linguística Aplicada) - Programa de Pós- graduação Interdisciplinar em Linguística Aplicada. Universidade Federal do Rio de Janeiro. Rio de Janeiro, 2007.

NASCIMENTO, Fernanda. G. A voz em estúdio: o uso audiovisual da dublagem e do diálogo pós-sincronizado no Brasil. 2014. 116f. Dissertação (Mestrado em Meios e Processos Audiovisuais) - Programa de Pós-Graduação em Meios e Processos Audiovisuais da Escola de Comunicações e Artes. Universidade de São Paulo. São Paulo, 2014.

Recebido em 15 de agosto de 2018.

Aceite em 26 de junho de 2019.

\footnotetext{
A partir de 2007, o canal pago FOX passou a exibir a maior parte de sua programação dublada (FERNANDES, 2007). Ao longo dos anos seguintes, mostrou-se uma tendência nos demais canais por assinatura brasileiros (GENESTRETI, 2015).

i"A autora considera o termo apenas no singular, uma vez que "ocorre num processo social, cultural, linguístico e cognitivo que se modifica e enriquece ao longo da vida dos indivíduos, membros de sociedades letradas. Nesse sentido, nos parece mais lícito falar em práticas ou eventos de letramento, quando se pretende pontuar as diferentes faces do fenômeno" (VERGNANO-JUNGER, 2105, p. 58).

iii No Brasil, para ser dublador, necessita ser ator profissional. Para obter o registro profissional de artista/ator ou atriz na Delegacia Regional do Trabalho, é necessário: graduação em Artes Cênicas, curso de formação de ator de Nível Médio ou experiência comprovada na área junto ao Sindicato dos Artistas e Técnicos em Espetáculos de Diversão (SATED).
} 